This item was submitted to Loughborough's Research Repository by the author.

Items in Figshare are protected by copyright, with all rights reserved, unless otherwise indicated.

\title{
A built environment response to the rising costs of dementia
}

PLEASE CITE THE PUBLISHED VERSION

http://dx.doi.org/10.1108/JFMPC-06-2015-0019

PUBLISHER

(c) Emerald

VERSION

AM (Accepted Manuscript)

\section{PUBLISHER STATEMENT}

This work is made available according to the conditions of the Creative Commons Attribution-NonCommercialNoDerivatives 4.0 International (CC BY-NC-ND 4.0) licence. Full details of this licence are available at: https://creativecommons.org/licenses/by-nc-nd/4.0/

\section{LICENCE}

CC BY-NC-ND 4.0

\section{REPOSITORY RECORD}

Pantzartzis, Efthimia, Andrew Price, and Federica Pascale. 2016. "A Built Environment Response to the Rising Costs of Dementia”. Loughborough University. https://hdl.handle.net/2134/21351. 


\title{
A built environment response to the rising costs of dementia
}

\begin{abstract}
Purpose - This paper identifies costs related to dementia care provision and explores how purposeful built environment investments can help control these costs and improve Quality of Life and clinical outcomes.

Design/methodology/approach - This research adopts a multi-method approach where the findings of a literature review drove the analysis of data obtained from the 115 pilot projects funded by the Department of Health England's National Dementia Capital Investment Programme.

Findings - Under the UK government's new productivity challenge, it is fundamental to identify actions that provide Value for Money in order to prioritise policy and practice. This paper identifies healthcare spaces (e.g. bathroom) where the impact of the built environment on healthcare costs are most evident, and building elements (e.g. lighting) to which these costs can be directly associated. The paper advocates the development of evidence and decision support tools capable of: linking built environment interventions to the healthcare costs; and helping the health and social care sectors to develop effective and efficient capital investment strategies.
\end{abstract}

Research limitations/implications - Further work needs to develop more systematic ways of rationalising pro-active and timely built environment interventions capable of mitigating dementia (and elderly) care cost escalation.

Originality/value - This research takes an innovative view on capital investment for care environments and suggests that appropriate built environment interventions can have a profound impact on costs associated with dementia care provision.

Keywords - Built environment; care provision; costs; dementia; dementia-friendly; healthcare; Quality of Life; social care; Value for Money.

Paper type - Research paper

\section{Introduction}

\section{Ageing populations worldwide}

The World Health Organisation (WHO) reported that people aged over 65 or above will account for 1.5 billion of the world's population by 2050; rising from 524 million in 2010 (WHO - National Institute on Aging - National Institutes of Health, 2011). In the past two decades, the number of people in the EU aged over 65 years increased by 3.6 per cent (Giannakouris, 2010). In 2012, people aged 65 years and above accounted for 17.8 per cent of the 27 EU Member States population (Robustillo et al., 2013), and was projected to increase to: 23.5 per cent by 2030; and 29.5 per cent by 2060 (Giannakouris, 2010). If fertility rates, mortality rates and levels of net migration keep convergent trajectories, the population of the 28 current EU Member States will remain with the highest old age dependency ratio in 2060 with a rise of between 20 and 25 per cent, compared to the world population which will remain below 14 per cent (European Commission and Economic Policy Committee, 2014). Ageing populations bring together a series of implications and co-morbidities: noncommunicable diseases; elderly related impairments; and long-term care (CSDH, 2008) requirements for people with reduced functional, physical or cognitive impairments (European Commission and Economic Policy Committee, 2014). 


\section{Increased dementia prevalence worldwide and in the UK}

Dementia is "a syndrome due to disease of the brain, usually of a chronic or progressive nature, in which there is disturbance of multiple higher cortical functions, including memory, thinking, orientation, comprehension, calculation, learning capacity, language and judgement. Consciousness is not clouded. The impairments of cognitive function are commonly accompanied, and occasionally preceded, by deterioration in emotional control, social behaviour and motivation” (WHO, 2004). "Conditions associated with dementia are typically progressive, degenerative and irreversible, for which there is currently no cure" (Access Economics Pty Limited, 2009). There are several types of dementia which have differentiating symptoms and rates of progression. People living with dementia may: lose their inhibitions; find social situations challenging; lose interest in socialising and their usual activities; become apathetic; have difficulty finding the right words and objects; and present loss of personhood and a reduced perception of time and space.

"Globally, it is estimated that 24.3 million people have dementia, with 4.6 million new cases of dementia being diagnosed every year. The numbers of people affected will double every 20 years to 81.1 million by 2040" (Fleming and Purandare, 2010). With nearly 7.7 million new cases each year worldwide (WHO, 2012), and higher prevalence in developing countries expected to reach 71 per cent in 2040 (Ferri et al., 2005), dementia has become of increasing concern to many countries.

In the UK, "dementia presents a huge challenge to society, both now and increasingly in the future" (Department of Health, 2009). In 2011, an estimated 750,000 people were living with dementia in the UK, however, the Health Foundation report (Matrix Evidence, 2011) suggested that "the true figure could be three times as high, compared with almost 669,000 aged over 65", due to continued failure to correctly and timely diagnose people with dementia. In 2015 there were approximately 850,000 people with dementia and over 1 million people are expected living with dementia in the UK by 2025 and over 2 million by 2051 (Alzheimer's Society, 2014; Ray and Davidson, 2014).

\section{Financial pressures on the health and social care built environment in the UK}

"Given the demographic implications of ageing and the expected increase of the number of people with dementia, the provision of care environments which meet their needs becomes critical” (Hadjri et al., 2012). The healthcare sector is coming under increased pressure to deal with this challenge (Appleby et al., 2010; Appleby et al., 2014), and the sustainability of future investments needs to be based on tangible evidence of how purpose-built environments can provide best Value for Money (VfM).

The situation is made worse by the fact that, 17 per cent of the current National Health Service (NHS) England's built infrastructure is outdated, no longer fit for purpose and reported "not functionally suitable" (Department of Health, 2010). The inadequate buildings can determine unacceptable risks for and cause further harm to patients, staff and visitors, as outlined in the Mid Staffordshire NHS Foundation Trust Public Inquiry (Francis, 2013). Mills et al. (2015) provided evidence of investments needed to maintain critical backlog ${ }^{1}$ maintenance levels, which can affect levels of safety, thus adding further pressures on the system.

\footnotetext{
${ }^{1}$ Critical backlog is the total backlog cost relating to significant and high risk sub-elements for the building/block (NHS Estates 2004. A risk-based methodology for establishing and managing backlog London: The Stationery Office.)
} 
In the UK, NHS expenditure has rapidly increased from $£ 11.4$ billion in 1948, when the NHS was created, to $£ 121$ billion in 2010/11 (Harker, 2012). "Growth in healthcare has far outpaced the rise in both gross domestic product (GDP) and total public expenditure: each increased by a factor of around 4.8 per cent over this period" (Harker, 2012). The average rate of spend (capital and operating) ${ }^{2}$ on UK NHS has risen by average 3.7 per cent in real terms since 1948 (Lafond, 2015). The overall figure of $£ 822$ million (i.e. $£ 349$ million for 130 Foundation Trusts, and $£ 473$ million for other NHS Trusts) annual deficit (Monitor, 2015) drives the need for innovative solutions that can improve productivity and capital investments.

\section{Aim and objectives of the paper}

This paper aims to explore the costs associated with dementia care provision and advocates strategies to mitigate the existing gaps to make care environments more dementia-friendly thereby improving the Quality of Life (QoL) for people living with dementia whilst reducing the associated cost of care provision.

This paper: 1) reviews dementia care provision direct and indirect costs; 2) explores how the built environment can affect these costs; and 3) reviews the available tools developed to support and monitor the effectiveness of dementia care environments.

\section{Methodology}

Figure 1 describes the multi-method research methodology adopted, in which the findings of (1) a literature review which drove the analysis of (2) the 115 pilot projects funded by 2013/14 DH England's National Dementia Capital Investment Programme (NDCIP) (Price et al., 2015), during which the authors monitored the progress and the impact of the projects, analysed the data and reported to $\mathrm{DH}$. This approach has been adopted to provide a contextualisation of the problem and explanation of how it has been addressed.

The review (1) gathered evidence from multiple international sources, including research papers, reports, government and non-governmental codes, with the intention to provide consistency to the expected outcomes (Walsh and Downe, 2005; Weed, 2005). The research question of how the built environment can be designed and built to mitigate escalating costs of dementia care provision has been addressed via three main areas, around which literature was collected and organised: a) the costs of dementia care provision; b) the impact of the built environment on dementia care outcomes; and c) the available tools to support, monitor and measure dementia care environments. As proposed by Noblit \& Hare (1988), the interpretation of the sources within each area helped to identify, evaluate and integrate key elements that were then analysed and rationalised into gaps and issues that could potentially improve understanding and offer solutions. NVivo $($ software was used to code the data sources and analyse the existing gaps.

The NDCIP (2) offered the unique opportunity to explore the link between the built environment and dementia costs. The results from the literature review were enriched by analysis of primary data collected during the NDCIP related to the built

\footnotetext{
2 The Private Finance Initiative (PFI) introduced in 1997, despite reducing the capital spending, has increased the long-term commitment to operating costs, with PFI contracts increasing by 48 per cent in real terms between 2009/10 and 2013/14 (Lafond, S. 2015. Current NHS spending in England. London, UK: The Health Foundation.)
} 
environment interventions and their costs, thus providing evidence of how funds were spent. Primary data from the 115 pilot projects included: a) types of settings, spaces and components of the built environment as reported in their initial applications; and b) the costs of the interventions, reported in their final individual reports. A statistical analysis was conducted in MS Excel@ to identify percentage of: the space types as in Figure 2a and 2b; the building components as in Figure 3a and 3b; and the awarded sum spent on building components as in Figure 5.

\section{PLEASE INSERT FIGURE 1 from PowerPoint file}

Figure 1. Research methodology

\section{The costs of dementia care provision}

\section{Dementia care provision: financial pressures and cost assessment}

The cost of dementia care worldwide is around $\$ 600$ billion (WHO, 2012; Department of Health, 2013). Current estimates are that the cost in the UK is $£ 26.3$ billion a year, of which only $£ 4.3$ billion are directly related to healthcare: $£ 10.3$ billion accounts for social care expenditure and $£ 11.6$ billion are estimated for the work of unpaid carers (Alzheimer's Society, 2014).

Assessments of dementia care costs are subject to diagnoses of: the condition; type and level of dementia; type of care provided; and setting in which the care is provided (Schaller et al., 2015). Langa et al. (2001) demonstrated how the costs associated with informal care sharply increase as cognitive impairment worsen. Wimo et al. (2007) estimated the worldwide societal costs of dementia in 2005 to be $\$ 315.4$ billion for a dementia population of 29.3 million people, including direct medical and non-medical costs and informal care, which accounted for 33 per cent of the overall figure. Indirect costs are exceptionally difficult to quantify as there is no systematic definition adopted. Furthermore, as many people live with dementia in a variety of public/private and clinical/residential settings, the complexity associated with gathering comprehensive information increases (Wanless, 2006). At present there is no alike set of principles nor a shared approach to determine the costs of dementia care, which affects the quality of the existing data (Wimo et al., 2011; Schaller et al., 2015).

Consequently, multiple types of classification can be explored and applied. In this paper, dementia costs have been grouped by a hierarchical clustering method (Milligan and Cooper, 1987) as: direct health care; direct social care; and indirect costs (see Figure 2).

\section{PLEASE INSERT FIGURE 2 from PowerPoint file}

Figure 2. Clustering costs related to dementia care

\section{Direct health care costs}

Older people occupy up to 70 per cent of acute hospital beds and up to 50 per cent may be people with cognitive impairments, including dementia (Department of Health, 2009). An estimated 25 per cent of hospital beds are occupied by people living with 
dementia (Alzheimer's Society, 2009) and account for 'hospital care' (Department of Health, 2013). For many people living with dementia, hospitals remain a challenging environment, where they have worse outcomes in terms of Length of Stay (LoS), mortality and institutionalisation than people who do not (Alzheimer's Society, 2009). Direct health care costs account for all expenditure directly related to the healthcare provided to dementia patients in acute settings: costs associated with dementia diagnosis and treatment include the cost of hospital staff, drugs and medications, and hospital care, to which additional costs related to events such admissions/readmissions, visits to clinics and GPs, and access to Emergency Departments (EDs) supplement. UK dementia direct health care costs were estimated to be $£ 8$ billion a year (Matrix Evidence, 2011). Table 1 summarises the available evidence on some of these costs.

\section{PLEASE INSERT TABLE I from Word file}

Table 1. Estimated dementia direct medical cost care provision

Incidence rates for falls are two to three times higher in hospitals and nursing homes compared to community settings (Skelton and Todd, 2005). Hospital admissions due to falls significant impact direct health care costs and LoS of patients with dementia (Mitchell and Bateman, 2012). Patients who have fallen once are at a higher risk of falling again (Myers, 2003; Oliver et al., 2004; Skelton and Todd, 2005) and over 200,000 people per year are admitted to hospital for treatment after a fall (National Institute for Health and Clinical Excellence, 2004). During 2004-05, there were over 46,000 admissions for fractured neck of femur alone (Hospital Episodes Statistics, 2005) and patients with dementia are more likely than those without to require hospital admission (Hubbard et al., 2004).

For people living with dementia, the average LoS after a hip fracture was 43 days, compared to 26 days for patients who were psychiatrically well. Chen, Liu et al. (2010) confirmed the relationship between: cognitive impairment and the mental state of dementia patients; and number of falls in tertiary healthcare settings. The Alzheimer's Society (2009) reported that 25-35 per cent of patients with dementia admitted due to consequences of falls remained in hospital for over one month. An additional 4.2 million inpatient bed-days were for other problems of people living with dementia (as a secondary diagnosis) compared to estimated 1.5 million bed-days for dementia itself (Matrix Evidence, 2011).

The Alzheimer's Society (2009) stated that, by reducing the LoS of people with dementia in hospital by a week, the NHS could save $£ 80$ million a year for just four common conditions. Furthermore, in nursing homes, residents with dementia were nearly twice as likely to fall as those without dementia even when other important risk factors were controlled. They also had significantly more injurious fall rates. (Van Doorn et al., 2003).

In 2014 around £85 million were spent on diagnosis in the UK (Alzheimer's Society, 2014). Incorrect and late diagnosis of people with dementia results in an increase in health care costs, due to subsequent and repeated diagnostic examinations (e.g. patient travel time; staff working hours; use and maintenance of equipment; examination material; and drugs).

Five per cent of total costs related to dementia are estimated for medication costs, to which inappropriate use of antipsychotic drugs added to (Matrix Evidence, 2011). 
Hospital staff costs have been affected in recent years by a rise in the number of bank and agency staff employed often associated with high staff turnover rates due to the challenge of managing the needs of people living with dementia. NHS spending on temporary staff increased by an average 9 per cent a year between 2009/10 and 2013/14, as opposed to an average 4 per cent a year for permanent staff (Lafond, 2015). In the effort to put in place specific dementia awareness training for the entire NHS staff by 2018, additional costs were added onto the system.

Visits to General Practitioners (GPs) and clinics are clustered in direct health care costs as older people with dementia frequently have other diseases and medical problems that require prescriptions and treatment. In 2008, there were 7 million GP consultations for people living with dementia, half of which were home visits. Almost 300,000 were visits to EDs and 490,000 were outpatient consultations for people with dementia.

\section{Direct social care costs}

The Alzheimer's Society (2014) estimated 38 per cent of people with dementia in the UK live in care homes (i.e. 180,500 people are living in residential care and 131,200 in nursing care). Most social services costs for people living with dementia in England can be clustered as: residential care; nursing care; extra-care and home care; with a smaller expenditure on other services such as equipment and adaptations or day care (Matrix Evidence, 2011; Alzheimer's Society, 2014). Direct social care costs relate to expenditure directly associated with social care provided to dementia residents in community settings, and include $£ 4.5$ billion care funded by the public sector (i.e. 17.2 per cent) and $£ 5.8$ billion care funded by the private sector (i.e. 22.9 per cent) (Alzheimer's Society, 2014). They include care provided in private homes, residential homes and long-term facilities, after acute clinical phases, when people require hospitalisation, and when patients need constant daily attention. Approximately twothirds of care home residents are estimated to have dementia (Department of Health, 2013). The direct UK social care costs in 2013 were $£ 10,271$ million, which corresponds to average $£ 12,584$ per person per year (Alzheimer’s Society, 2014). Table II offers an indicative summary of the costs per year, which prove to be higher in residential settings.

\section{PLEASE INSERT TABLE II from Word file}

Table I1. Estimated dementia direct social care cost provision

The Health Foundation estimated that 40 per cent of total dementia care costs related to long-term residential care (Matrix Evidence, 2011). Social services expenditure on older people increased to £9.1 billion while non-residential expenditure on day/domiciliary services increased to $£ 6.5$ billion in 2008-09 (Matrix Evidence, 2011).

\section{Indirect costs}

Most people with dementia live in the community (Brodaty and Donkin, 2009): between 70 per cent and 81 per cent in the USA (Alzheimer's Association and National Alliance for Caregiving, 2004) and approximately 66 per cent in the UK (Alzheimer's Society, 2013). Support is not only needed by people who experience the condition, but also by their families and carers. People acting as the primary carers for people living with dementia are estimated to 10 million in the USA (Alzheimer's Association, 2007) and over 670,000 in the UK (Alzheimer's Society, 2011). 
On top of direct health and social costs are others which are often not immediately evident, such as: indirect costs accounting for events/conditions that occur as a consequence of living with dementia; and indirect costs relevant to unpaid care. In 2014, the Alzheimer's Society estimated these costs to be 44 per cent of the total cost of dementia care. Table III provides a summary of the available estimated indirect costs per year.

\section{PLEASE INSERT TABLE III from Word file}

Table III. Estimated dementia indirect care cost provision

It has been estimated that: a total of 512 million hours are spent caring for people living with dementia by economically active carers, and 997 million hours from noneconomically active carers; and a person with severe dementia living in the community typically requires 46 hours of carer support per week (Matrix Evidence, 2011).

In the US in 2012, the 15.4 million families and other unpaid caregivers of people with Alzheimer's disease and other types of dementia provided an estimated 17.5 billion hours of unpaid care. At an average of 21.9 hours of care per caregiver per week, or 1,139 hours of care per caregiver per year, with this care valued at $\$ 12.33$ per hour, the estimated economic value of care provided by family and other unpaid caregivers of people living with dementia was $\$ 216.4$ billion (Alzheimer's Association, 2013).

In the UK, the total cost of unpaid care accounts for three-quarters (i.e. 74.9 per cent) of the total cost for people with dementia living in the community (Alzheimer's Society, 2014). Matrix Evidence (2011) reported a $£ 270$ cost per resident per week for unpaid care, with the carer time estimated at the minimum national wage, while the Alzheimer's Society (2014) following a Swedish study estimated the time spent by unpaid carers of people living with dementia is 14 per cent of time to assist with activities of daily living $^{3}$ (ADLs), 35 per cent of time with instrumental activities of daily living ${ }^{4}$ (IADLs), and 51 per cent of time on supervision/surveillance.

Unpaid carers (mostly female family members) provide most of community care (Wanless, 2006), which accounts for three-quarters of the total cost (Wanless, 2006; Alzheimer's Society, 2014). However, smaller families, divorce and changing expectations may mean a reduced supply of unpaid carers in the future. There is evidence that between a half and two-thirds of unpaid carers are either not: receiving a carer's assessment; having the assessment followed up; or having their needs met once assessed (Luengo-Fernandez et al., 2010).

In 2012, the "physical and emotional impact of dementia caregiving" was estimated to be $\$ 9.1$ billion in additional health care costs in the USA (Alzheimer's Association, 2013 ). The physical and psychological health of the caregivers accounts for indirect costs as well, as the high demands of people living with dementia affect their working and personal lifestyle. Full-time or part-time employed dementia caregivers (i.e. about 60 per cent of all caregivers) had to make major changes to their work schedules: 65 per cent had to go in late, leave early or take time off and 20 per cent had to take a leave of absence (Alzheimer's Association, 2013 ).

\footnotetext{
${ }^{3}$ Activities performed to fulfil basic needs (e.g. toileting, dressing and eating).

${ }^{4}$ Activities performed to live independently in a community (e.g. cleaning a room, preparing a meal and going to shop).
} 
"Specifically, family caregivers of people with dementia may experience greater risk of chronic disease, physiological impairments, increased health care utilization and mortality than those who are not caregivers. Forty-three per cent of caregivers of people with Alzheimer's disease and other dementias reported that the physical impact of caregiving was high to very high" (Alzheimer's Association, 2013 ). As people living with dementia generally require high levels of care (Brodaty and Donkin, 2009), caring can be an overwhelming experience, bringing irreversible changes to lives and relationships (Alzheimer's Society, 2011).

\section{The impact of the built environment on dementia care outcomes}

Previous research has demonstrated: the importance of physical environments on the QoL of people living with dementia (Kovach et al., 1997; Lawton, 1997; Brod et al., 2000; Day et al., 2000; Calkins, 2004; Reimer et al., 2004); and that physical environment design features can be associated with quality of care, and behavioural and clinical outcomes (Kovach et al., 1997; Marshall et al., 1999; Day et al., 2000; Devlin and Arneill, 2003; Gitlin et al., 2003; Zeisel et al., 2003; Calkins, 2009). Research has related the built environment and its design features to most dementia related symptoms. Table IV below summaries evidence on the impact of specialist dementia care built environments on people living with dementia, including spaces and specific building elements, such as: lighting; way-finding elements; furniture; design layout; and sensory gardens.

\section{PLEASE INSERT TABLE IV from Word file}

Table IV. Evidence on the impact of specialist dementia care environment

The current body of knowledge has limitations. Despite the available evidence about different needs of people living with dementia at different stages of the syndrome, there is lack of consideration of these stages and especially of the final stage in the design process (Fleming and Purandare, 2010). Furthermore, there is a little scientific research on the impact of the built environment on dementia caregivers, medical staff and visitors (e.g. families and carers) (Zeisel et al., 2003; Wood et al., 2005), although their involvement is well demonstrated (Hall and Skelton, 2012). Claims that "much environmental research being inconclusive and limited in usefulness" (Wood et al., 2005) and "little being certain" (Fleming et al., 2008) need to be taken into account. These issues can be attributed to: (1) methodological challenges (e.g. small samples, types of setting, measurement of relevant outcomes and environmental features) (Kovach et al., 1997; Gitlin et al., 2003); (2) lack of discernment between the effect of environment and of staff treatment activities (Sloane et al., 1998); and 3) lack of consideration of the different stages of the disease, especially the final stage (Fleming and Purandare, 2010). For these reasons, and although, progress has been made during the last 30 years (Calkins, 2009), evidence on environmental strategies ability to impact positively on patients' outcomes requires further work (Gitlin et al., 2003; Fleming and Purandare, 2010). 


\section{The available tools to support, monitor and measure dementia care environments}

Quantitative tools have been used to monitor and measure dementia care environments, including: Multiphasic Environmental Assessment Procedure (MEAP); Therapeutic Environment Screening Survey for Nursing Homes (TESS-NH); and Professional Environmental Assessment Protocol (PEAP). Limitations have been identified with those tools, which do not focus only on the environmental aspects, but also require extensive knowledge and time to effectively rate the built environment and determine its quality.

More recently, a new class of assessment tools has been developed: such as: the Environmental Audit Tool (EAT) by NWS Department of Health (Australia); and the Design for Dementia Audit Tool (DDAT) by the Dementia Services Development Centre (DSDC) at the University of Stirling (UK). Table V summarises the main components and limitations of these tools.

\section{PLEASE INSERT TABLE V from Word file}

Table V. Quantitative tools relevant to specialist dementia care environment

Most of the criteria or principles, considered in the above tools, are general and do not allow evaluation of specific impact and of the value of different interventions. The tools currently in use monitor and measure dementia care environments through a variety of factors. Among them there is a recognised focus on the built environment and a number of environmental aspects, in some occasions linked to the people clinical outcomes. As people living with dementia are increasing, along with a raise in direct and indirect costs of care, there is need to further develop these tools to promote sustainable capital effectiveness based on the socio-economic value of different types of dementia-friendly environments.

\section{UK response: the DH England National Dementia Capital Investment Programme}

The Programme and the case studies

With the publication of "Living well with dementia: A National Dementia Strategy" (Department of Health, 2009), Dementia became a UK national priority, however, more needs still to be done as recognised in 2012, when the Prime Minister launched the "Challenge on Dementia". To reduce future pressures on the NHS and social care providers without compromising the QoL of people living with dementia, the Prime Minister's (PM) Challenge on Dementia identified three key areas: (1) driving improvements in health and care; (2) creating dementia-friendly communities that understand how to help; and (3) promoting dementia related research (Department of Health, 2012). This will remain among the UK top priorities for the next five years (Department of Health, 2015b).

The NDCIP "Improving the environment of care for people with dementia" was announced in 2012, with a $£ 50$ million fund for the creation of custom designed care facilities for people with dementia in health and social care environments. The DH allocated: (1) £25 million to Local Authorities (LAs) working in partnership with social care providers; and (2) £25 million to NHS providers for 115 national pilot projects. 
These pilots were intended to promote service user well-being and foster dementiafriendly environments to meet 14 potential core outcomes: 1) QoL; 2) dignity; 3) privacy; 4) independence; 5) therapeutic value of garden areas; 6) responsiveness dementia care providers; 7) nutrition; 8) cultural diversity; 9) provider's ability to meet multiple complex needs; 10) comfort and safety; 11) stress and anxiety; 12) aggressive and disturbed behaviour; 13) slips, trips and falls; and 14) inequalities.

\section{Pilot projects: settings, spaces and building components}

The pilot projects included a large variety of settings and included 'integrated' projects, with physical interventions across different settings to integrate the care pathway across health and social settings: Figures 3a and 3b present the spaces; and Figures $4 \mathrm{a}$ and $4 \mathrm{~b}$ present the building components that were implemented the most during the NDCIP.

These provide a clear understanding of what interventions the health and social care sector considered as relevant to meet these outcomes. Although multiple spaces were included by the 115 pilot projects throughout the programme, the focus was on public spaces (in care settings), where people with dementia should spend most of their days to interact with others and keep their sensory, cognitive and physical functions active to improve their QoL.

Interventions on gardens accounted for 50 per cent of the spaces chosen to implement dementia-friendly built environments by NHS case studies. Day areas and circulation spaces together with bathrooms resulted to have higher priority than bedrooms, which only account for 26 per cent of interventions. Less than five per cent of the pilot projects suggested end-of-life care rooms.

Social care pilot projects confirmed the focus of project interventions on garden areas, which include indoors spaces such as patios, with a percentage of 75 per cent. Even though all other proposed interventions were less than 40 per cent, Figure $3 \mathrm{~b}$ indicates the same priorities as in the NHS pilot projects: day areas, circulation spaces and bathrooms. The functional areas that were to be considered as well are therapy/activity spaces, dining rooms and sensory/reminiscence spaces.

\section{PLEASE INSERT FIGURE 3a and FIGURE 3b from Excel file}

Figure 3a and Figure 3b. Percentage of the space types for NHS and social care (LA) case studies from the DH Dementia Capital Programme

Figure 4a and Figure 4b demonstrate the diversity of components that can be modified to create dementia-friendly environments. The most implemented building components by both the NHS and social care projects were: flooring finishes, colour, signage, lighting, artwork (i.e. NHS) and furniture (i.e. social care). In addition, significant innovations were recorded in the proposed use of technology and artwork.

NHS pilot projects planned interventions on: flooring finishes, above 70 per cent; colour coding and signage, around 50 per cent; lighting and artwork, 45 per cent. Social care pilot projects proposed interventions to: flooring finishes, above 50 per cent; signage, above 60 per cent lighting and furniture, more than 45 per cent. Whilst a large number of projects aimed at improving the outdoors, as detailed in Figure $4 \mathrm{~b}$, a limited number of interventions were planned to make the external environment more accessible. 


\section{PLEASE INSERT FIGURE 4a and FIGURE 4b from Excel file}

Figure 5a and Figure 5b. Percentage of the building components for NHS and social care (LA) case studies from the DH Dementia Capital Programme

Results from the analysis of the impact of the built environment on care outcomes: lighting

Forty-five per cent of NHS projects and 49 per cent of the social care projects proposed investments in lighting interventions (Department of Health, 2015a). The study recorded the impact of changes in lighting (e.g. type of light, colour of light, level of luminance, direction of lighting sources, reflection and diffusion, glare, system operability, flexibility of switching between different uses, and fixtures) on the QoL of people living with dementia. One of the pilot projects aimed at developing an exemplar physical environment for people with dementia and their carers in an acute hospital to support care delivery. The project implemented the use of: lighting, colour coding, reminiscence objects and dementia-friendly signage, while introducing social seating areas and activity rooms. The lighting interventions focused on introducing dynamic light-emitting diode (LED) lighting systems in all bed areas (i.e. private space) to simulate the natural circadian rhythm, which improves mood, behaviour and sleeping patterns in a 14 bedded older people medical ward. LED lighting systems and themed ceiling lighting were also introduced within corridors and activity rooms (i.e. public space). A 10 per cent reduction in falls compared to other medical wards over the first six months was recorded by the organisation. A significant decrease in the recorded number of slips, trips and falls was reported after February 2014, following the ward re-opening to the patients. By the end of the monitoring period, the recorded number of episodes stabilised at a relatively low value (i.e. less than 10 falls) compared to the maximum achieved pre-project monitoring period (i.e. almost 40 falls).

\section{Results from the cost analysis of the interventions}

Despite the maximum amount of money pilot projects were allowed to bid for to complete the physical interventions was $£ 1$ million per single application, there were 14 out of 65 social care pilots and one out of 42 NHS pilots with bids under $£ 50 \mathrm{k}$. During the programme, each pilot project provided monthly data on the economic progress of their works. The Pilot Projects focused on interventions, which were rationalised in the following 14 core Design Features: 1) acoustics; 2) artwork; 3) ceilings; 4) colour; 5) decoration; 6). doors; 7) fixtures; 8) flooring; 9) furniture and fittings; 10) lighting; 11) reminiscence hardware and software; 12) signage; 13) walls; and 14) windows and transparent panels.

To determine on which components of the built environment the pilots projects had spent most of the awarded DH fund, a sample of 27 pilot projects (i.e. 12 NHS and 15 social care), were analysed. These pilot projects were selected as they had reported the elemental cost breakdown per components of the built environment in a detailed way at the end of their projects. The amount spent by this sample on the components of the built environment was $£ 4,029,459$. From the analysis of provided data, it emerged that improving the quality and the appearance of the built environments for care was one of the main goals. Most of the awarded capital was spent on decoration, furniture, artwork, fittings and fixtures, as presented in Figure 5. 
Figure 5. Percentage of the awarded sum spent on building components for NHS and social care (LA)

case studies sample from the DH Dementia Capital Programme

Sixteen per cent of the awarded sum was used to replace doors and improve lighting, which improve the safety performance (e.g. high visibility enhances independence and navigation) in addition to the quality of the built environment. A total of 10.5 per cent of the sum was spent to replace flooring, which highlights how issues related to safety are considered as high priority, and slips, trips and falls were one of the recorded performance indicators. Approximately seven per cent of the fund was used to introduce reminiscence objects (e.g. memory boxes and memory walls) and reminiscence pods within the built environment, and to integrate reminiscence software in the occupational therapy.

\section{Results from analysis of $\mathrm{DH} 14$ core outcomes}

The pilot projects provided data on how each of the completed physical interventions (i.e. building component) supported the DH 14 core outcomes. NHS and social care pilots showed a moderate correlation in the way they ranked the 14 outcomes, which were not influenced by the amount awarded and spent on each project. Signage, colour coding and furniture were consistently upgraded by the NHS case studies as they recognised as being key elements of the built environment to meet all the 14 core outcomes. In particular: signage was identified as extremely relevant to "encouraging independence"; "promoting privacy"; and "promoting dignity"; and furniture has been related to "enhancing the physical environment to allow better nutrition". The NHS organisations recognised the importance of colour coding to meet a larger number of the 14 core outcomes, including: "promoting dignity"; "encouraging independence”; "reducing stress and anxiety"; and "reducing slips, trips and falls".

\section{Results from the King's Fund Enhancing the Healing Environment toolkit}

In 2008, the DH commissioned to King's Fund “Environments of Care for people with Dementia programme”, as part of the work to support the National Dementia Strategy. This programme assessed the completion of 26 projects in different types of hospital to improve the care environment for people affected by dementia and developed the EHE Environmental Assessment tool able to help organizations to design more supportive environments for people with dementia.

As part of the selection process for the NDCIP, applicants were asked to use the EHE tool to identify and prioritise the areas that needed interventions to make the environment "dementia-friendly". The way the EHE tool was used by some of the pilot projects indicates how this and the other available tools can be used, and paves the way towards more structured approaches to monitor and measure the impact of dementia-friendly care environments over the future.

\section{Discussion of results}

\section{Dementia costs}

Despite the progress towards planned and controlled strategies and actions, the accuracy of data on dementia costs presents challenges. The literature suggested that only a limited number of studies have been so far capable to identify elemental costs in mono-thematic researches (e.g. flooring, and lighting). The NDCIP demonstrated 
how difficult can be to monitor cost interventions when a mechanism is not in place. The direct costs not always take into account: longer LoS in hospitals, due to consequences of injurious falls; frequent staff turnover; and inappropriate use medications. Besides, the indirect costs associated to informal care are hardly taken into account, because of the lack of knowledge.

\section{Dementia-friendly built environment: settings and spaces}

The built environment can be either the health or social setting, and over the longterm it could become the home setting; thus there are a number of spaces in which the costs are more evident and a number of building elements to which these costs can be directly associated.

The prevalence of spaces in which people are expected to spend most of their daytime (i.e. day and circulation areas) and of spaces which should allow them to an independent and dignified QoL (i.e. bathrooms) clearly demonstrated the importance of built environment impact on the quality of care of people with dementia. Evidence on the impact of gardens, courtyards and conservatories on the QoL of people living with dementia drove the NDICP interventions in the outdoor spaces, which accounted for 50 per cent.

\section{Dementia-friendly built environment: building components}

The analysis of the 115 pilot projects identified flooring, signage, lighting and colour coding, followed by artwork and furniture, as the building components as having a greater impact on people living with dementia. Those were successfully related to the 14 DH's core outcomes, demonstrating the strong correlation between specific building elements and physical well-being. It was not identified a substantial difference between the analysed sample of health (NHS) and social (LAs) care settings, which might suggest that the impact of the built environment on people living with dementia does not necessarily require a preliminary distinction between types of interventions in health (e.g. acute) and social (e.g. community) care settings.

\section{Impact of the built environment on QoL}

The projects' cost data breakdown gathered during the NDCIP offered the opportunity to estimate some of these costs per building components, underlying the importance of safety and quality issues (e.g. flooring and lighting) together with elements of artwork and decoration, which enhance the well-being of people living with dementia.

The analysed sample of 27 pilot projects demonstrated that decoration, furniture, flooring, artwork, fittings and fixtures, doors, and lighting were the building components on which the organisations mostly invested the awarded fund, as reported in Figure 7. All these interventions had a great impact on the QoL of people with dementia, in health and social care settings, opening up opportunities to create dementia-friendly environments, even in institutional settings, such as acute hospital wards. The impact of the built environment (e.g. lighting interventions) on care outcomes (e.g. falls related to dementia) can improve the QoL of people, who will not require admission to ED due to a fracture, who will require a shorter stay in hospital, who will be mobile enough to independently complete his/her ADL with dignity. If the built environment supports people living with dementia, the need for clinical treatments may be contained, thus reducing the overall dementia costs.

\section{Driving costs down through quality and safety}

It is fundamental to identify and prioritise interventions that can have real impacts on different users and deliver VfM to avoid escalation of the NHS deficit over the future 
years and to implement a more integrated health and social care delivery, which effectively and efficiently capitalises on the available resources and does not require unpaid work to look after the growing elderly population.

The NDCIP has provided initial evidence that costs to deliver dementia-friendly built environments can be built into organisations' strategies, so that cheaper interventions (e.g. artwork and furniture) can be supported by charities and/or investors, while more expensive interventions (e.g. lighting and flooring) can be planned into refurbishments. These investments on the built environment can be a viable opportunity to reduce direct health care costs (e.g. drugs and medications, hospital admissions due to falls) and direct social care costs (e.g. admissions to residential care, hours of day care). Also the impact of the purpose-built new environments on the quality of care and QoL of people living with dementia has instigated a progressive reduction on indirect costs (e.g. hours of unpaid care, lost/part-time employment, stress-related diseases) for the informal carers, as the people they care for have experienced calmer and safer environments, in which they are better enabled to live as closer as possible to their lifestyles prior to the on-set of dementia. Quality and safety of the built environment in which people with dementia live can contribute to reduce some of these costs (e.g. dementia-friendly flooring can reduce injurious falls). Nonetheless, a common approach is not in place yet to monitor and record those costs.

\section{Person-centred design approach}

The research has investigated the impact of the built environment on the QoL and wellbeing of people living with dementia. The NDCIP demonstrated how a national coordinated strategy can implement knowledge and skills at local level. The lessons learnt led to the definition of twelve design principles (Department of Health, 2015a) that respond to: sensory, cognitive, and physical impairments. The built environment can offer be-spoke solutions that can be cost-efficient for an individual organisation towards improving the QoL and wellbeing of a person who may have sensory impairments rather than another person experiencing physical impairments.

A person-centred design approach can reveal solutions that may be advantageous to an organisation, in a specific context (i.e. site and space) and/or for a specific intervention (i.e. building component). Dementia-friendly built environments need to promote design principles (e.g. promote a safe environment; provide optimum levels of stimulation; and support orientation). This work intends to set a milestone in a design journey that requires further action.

\section{The environmental assessment tools}

The lack of supporting tools capable of linking the interventions on the built environment to the cost factor emerged from the literature review. The available tools to evaluate the impact of the built environment on people living with dementia are not yet able to quantify those cost savings nor indicate financial investment strategies.

The gap identified in the current tools between dementia behavioural outcomes and the interventions on the built environment is a clear evidence that further research is needed to improve the existing methodologies and to integrate the cost factor, which is likely to guide all political, social and environmental policies not only in the most immediate future. The way in which the EHE tool has been used during the NDICP to identify and prioritise the areas that needed interventions to create dementia-friendly environments is a promising example that, even if the available tools are not able to quantify those cost savings, by improving the QoL of people living with dementia 
through built environment interventions it is possible to reduce the direct costs associated to health and social dementia care provision together with the indirect costs.

\section{Conclusions and recommendations}

Dementia presents a major challenge to the worldwide economy and action is required. Given its extensive scale and projection to increase over the next decades, reducing the costs associated to dementia care provision should be a priority for any country. Direct health and social care costs and indirect costs account for the current expenditure and greatly impact on the national economy, despite the lack of shared principles to identify those costs and record their economic value. Most people with dementia live in the community, with direct social care costs. However, there are also pressures on the direct health care costs, when people access EDs or stay in hospital for a higher number of days than those required by only their clinical conditions. Frequent staff turnover and inappropriate use medications in hospital settings add to those costs. Besides, the indirect costs associated to informal care are hardly taken into account, because of the lack of knowledge. Informal care poses additional economic pressures on the caregivers, as people living with dementia often require long periods of attention which also affect the QoL of the carers, determining a number of indirect costs not always evident.

The variety of settings in which dementia care is provided and of spaces where people with dementia live and perform ADL and IADL requires an integrated approach that can respond to their impairments. The building components identified and analysed can offer be-spoke solutions to improve QoL and wellbeing of each person. The built environment can have a significant impact on the costs identified (e.g. reduction of falls; reduced re-admissions due to discharge to inappropriate stepdown facilities; and reduction in use of medications). Some of the interventions are relatively low cost (e.g. high contrast toilet seats; and visible signage), thus more easily implementable; others might bring higher costs (e.g. flooring and lighting), but they might be built in routine maintenance and avoid additional needs of resources.

A specific building component of the built environment (e.g. lighting) can implement care outcomes (e.g. reduction of falls), thus improve QoL of people living with dementia. The available tools might not be enough supportive of a long-term strategy, and individually lack the strategic coherence of a flexible tool capable to guide the decision-making process of planning, developing and managing dementiafriendly built environments. In this regard, environmental assessment tools can help the health and social care sector in planning future capital investment strategies and guide the decision making process. Gaps have been identified in the current knowledge to create dementia-friendly built environments: a) cost monitoring should include direct and indirect costs; b) systematic processes should be in place; and c) tools capable to address specific building components should be made available.

This paper advocates a better understanding of where the impact of the built environment on direct and indirect care costs is most evident: to improve QoL of people living with dementia, and to help the health and social care sector develop evidence and decision support tools to enable effective and efficient long-term capital investment strategies. The NDICP offered the opportunity to demonstrate that a strategic and integrated response is possible, which may require joint efforts by different stakeholders and person-centred approaches with in-depth knowledge of the dementia condition. 


\section{Limitations}

Although the research has taken in consideration available international literature, tools and guidance, additional work needs to be developed to fill the gaps identified throughout this study, between dementia care provision costs and costs of intervention on dementia care purpose-built environments and between dementia behavioural outcomes and intervention on dementia care environments. More systematic ways towards a rationalisation of what interventions should be advocated on the built environment are crucial to develop pro-active and timely solutions. Further investigation of what the options might be to mitigate the escalation of dementia care provision costs and how decision support tools can help the healthcare sector in planning future capital investment strategies is needed, given the current economic climate.

\section{Acknowledgements}

PLEASE INSERT AKNOWLEDGMENTS from Word file2 


\section{References}

Access Economics Pty Limited 2009. Keeping dementia front of mind: incidence and prevalence 2009-2050. Australia: Alzheimer's Australia.

Alzheimer's Association 2007. Alzheimer's Disease Facts and Figures. Chicago, US: Alzheimer's Association.

Alzheimer's Association 2013. Alzheimer's Disease Facts and Figures. Chicago, US: Alzheimer's Association.

Alzheimer's Association \& National Alliance for Caregiving 2004. Families care: Alzheimer's Caregiving in the United States. Chicago, US: Azheimer's Association and National Alliance for Caregiving.

Alzheimer's Society 2011. Support. Stay. Save . Care and support of people with dementia in their own homes.

Alzheimer's Association 2013 Alzheimer's Disease Facts and Figures. Alzheimer's \& Dementia.

Alzheimer's Society 2009. Counting the cost. Caring for people with dementia on hospital wards. London, UK: Alzheimer's Society.

Alzheimer's Society. 2013. Statistics [Online]. Available: http://www.alzheimers.org.uk/statistics [Accessed 18 March 2013].

Alzheimer’s Society 2014. Dementia UK: Update. Second edition. London, UK: Alzheimer's Society.

Ancoli-Israel, S., Gehrman, P., Martin, J. L., Shochat, T., Marler, M., Corey-Bloom, J. \& Levi, L. 2003. Increased Light Exposure Consolidates Sleep and Strengthens Circadian Rhythms in Severe Alzheimer's Disease Patients. Behavioral Sleep Medicine, 1, 22-36.

Anderson, K., Bird, M., Macperson, S., McDonough, V. \& Davis, T. 2011. Findings from a pilot investigation of the effectiveness of a snoezelen room in residential care: should we be engaging with our residents more? Geriatric Nursing, 32, 166-177.

Appleby, J., Galea, A. \& Murray, R. 2014. The NHS productivity challenge. Experience from the front line. In: Fund, T. K. S. (ed.). The King's Fund.

Appleby, J., Ham, C., Imison, C. \& Jennings, M. 2010. Improving NHS productivity: More with the same not more of the same. . In: Fund, T. K. S. (ed.). The King's Fund.

Atkinson, A. 1995. Managing people with dementia: CADE units... confused and disturbed elderly. Nursing Standard, 9, 29-32.

Baker, R., Bell, S., Baker, E., Holloway, J., Pearce, R., Dowling, Z., Thomas, P., Assey, J. \& Wareing, L.-A. 2001. A randomized controlled trial of the effects of multi-sensory stimulation (MSS) for people with dementia. British Journal of Clinical Psychology, 40, 81-96.

Barrick, A. L., Sloane, P. D., Williams, C. S., Mitchell, C. M., Connell, B. R., Wood, W., Hickman, S. E., Preisser, J. S. \& Zimmerman, S. 2010. Impact of ambient bright light on agitation in dementia. Inernational Journal of Geriatric Psychiatry, 25, 1013-1021.

BBC 2015. Osborne says low productivity key economic challenge http://www.bbc.co.uk/news/uk-politics-32816451 [Accessed 22 May 2015].

Bellelli, G., et al., Special care units for demented patients: A multicenter study. Gerontologist, 1998. 38(4): p. 456-462.

Bianchetti, A., Benvenuti, P., Ghisla, K. M., Frisoni, G. B. \& Trabucchi, M. 1997. An Italian model of dementia special care unit: results of a pilot study. Alzheimer disease and associated disorders, 11, 53-56. 
Bleichrodt, H. \& Quiggin, J. 1999. Life-cycle preferences over consumption and health: when is cost-effectiveness analysis equivalent to cost-benefit analysis? Journal of Health Economics, 18, 681-708.

Brod, M., Stewart, A. L. \& Sands, L. 2000. Conceptualization of quality of life in dementia. In: Albert, S. M. \& Logsdon, R. G. (eds.) Assessing Quality of Life in Alzheimer's Disease. New York: Springer.

Brodaty, H. \& Donkin, M. 2009. Family caregivers of people with dementia. Dialogues in clinical neuroscience, 11, 217-228.

Calkins, M. P. 2004. Articulating environmental press in environments for people with dementia. Alzheimer's Care Quarterly, 5, 165-172.

Calkins, M. P. 2009. Evidence-based long term care design. NeuroRehabilitation, 25, 145-154.

Cassie, K. M. \& Sanders, S. 2008. Familial caregivers of older adults. . In: CUMMINGS, S. M., KROPF \& NANCY, P. (eds.) Handbook of Psychosocial interventions with Older Adults: Evidence-Based Approaches. Philadelphia: Haworth Press.

Chen, X., Liu, Y., Chan, D., Shen, Q. \& Van Nguyen, H. 2010. Characteristics associated with falls among the elderly within aged care wards in a tertiary hospital: a retrospective. Chinese Medical Journal 13, 1668-72.

Cohen-Mansfield, J. \& Werner, P. 1998. The effects of an enhanced environment on nursing home residents who pace. The Gerontologist, 38, 199-208.

Cox, H., Burns, I. \& Savage, S. 2004. Multisensory environments for leisure: promoting well-being in nursing home.

CSDH 2008. Closing the gap in a generation: health equity through action on the social determinants of health. Final Report of the Commission on Social Determinants of Health. Geneva: WHO.

Cunningham, C. 2009. Auditing design for dementia. Journal of Dementia Care, 17, 31-32.

Cunningham, C., Marshall M \& McManus M 2008. Design for Dementia: Audit Tool. Stirling: University of Stirling.

Day, K., Carreon, D. \& Stump, C. 2000. The therapeutic design of environments for people with dementia: A review of the empirical research. Gerontologist, 40, 397-416.

De Lepeleire, J., Bouwen, A., De Coninck, L. \& Buntinx, F. 2007. Insufficient Lighting in Nursing Homes. Journal of the American Medical Directors Association, 8, 314-317.

Department of Health 2009. Living well with dementia: A National Dementia Strategy. London: Department of Health.

Department of Health 2010. Estates Return Infromation Collection (ERIC) 2009/10. Leeds NHS Information Centre for Health and Social Care

Department of Health 2012. Prime Minister's Challenge on Dementia. Delivering major improvements in dementia care and research by 2015: A report on progress. London: Department of Health.

Department of Health 2013. Dementia. A state of the nation report on dementia care and support in England.

Department of Health 2015a. Health Building Note 08-02: Dementia-friendly health and social care environments.

Department of Health 2015b. Prime Minister's challenge on dementia 2020. London: Department of Health. 
Detweiler, M. B. \& Warf, C. 2005. Dementia wander garden aids post cerebrovascular stroke restorative therapy: A case study. Alternative Therapies in Health and Medicine, 11, 54-58.

Devlin, A. S. \& Arneill, A. B. 2003. Health care environments and patient outcomes a review of the literature. Environment and Behavior, 35, 665-694.

Doyle, C. 1991. How to Assess the Quality of Long Term Care. Centre for Health Program Evaluation.

Eriksson, S., Gustafson, Y. \& Lundin-Olsson, L. 2008. Risk factors for falls in people with and without a diagnose of dementia living in residential care facilities: A prospective study. Archives of Gerontology and Geriatrics, 46, 293-306.

European Commission \& Economic Policy Committee 2014. The 2015 Ageing Report. Underlying Assumptions and Projectin Methodology. In: Commission, E. (ed.) European Economy

Everitt, B. S. 1979. Unresolved Problems in Cluster Analysis. Biometrics, 35, 169181.

Fava, L. \& Strauss, K. 2010. Multi-sensory rooms: Comparing effects of teh Snoezelen and the Stimulus Preference environment on the behavior of adults with profound mental retardation. Research in Developmental Disabilities, 31, 160-171.

Ferri, C. P., Prince, M., Brayne, C., Brodaty, H., Fratiglioni, L., Ganguli, M., Hall, K., Hasegawa, K., Hendrie, H., Huang, Y., Jorm, A., Mathers, C., Menezes, P. R., Rimmer, E. \& Scazufca, M. 2005. Global prevalence of dementia: a Delphi consensus study. The Lancet, 366, 2112-2117.

Fleming, R. 2011. An environmental audit tool suitable for use in homelike facilities for people with dementia. Australasian Journal on Ageing, 30, 108-112.

Fleming, R. \& Bowles, J. 1987. Units for the confused and disturbed elderly: Development, design, programming and evaluation. Australasian Journal on Ageing, 6, 25-28.

Fleming, R., Crookes, P. A. \& Sum, S. 2008. A review of the empirical literature on the design of physical environments for people with dementia.: Dementia Collaborative Research Centres.

Fleming, R., Forbes, I. \& Bennett, K. 2003. Adapting the Ward for People with Dementia. Sydney, AU: NSW, Department of Health.

Fleming, R. \& Purandare, N. 2010. Long-term care for people with dementia: environmental design guidelines. International Psychogeriatrics, 22, 10841096.

Francis, R. 2013. Report of the Mid Staffordshire NHS Foundation Trust Public Inquiry. London.

Giannakouris, K. 2010. Population and social conditions. Statistics in focus. EurostatEuropean Commission.

Gitlin, L. N., Liebman, J. \& Winter, L. 2003. Are Environmental Interventions Effective in the Management of Alzheimer's Disease and Related Disorders?: A Synthesis of the Evidence. Alzheimer's Care Today, 4, 85-107.

Hadjri, K., Faith, V. \& McManus, M. 2012. Designing dementia nursing and residential care homes. Journal of Integrated Care, 20, 322-340.

Hall, L. \& Skelton, D. A. 2012. Occupational therapy for caregivers of people with dementia: a review of the United Kingdom literature. The British Journal of Occupational Therapy, 75, 281-288.

Harker, R. 2011. NHS funding and expenditure. In: STATISTICS, S. A. G. (ed.). House of Commons Library. 
Harker, R. 2012. NHS funding and expenditure. In: Statistics, S. a. G. (ed.). House of Commons Library.

Healey, F. \& Scoble, S. 2007. Slips, trips and falls in hospital. PSO/3. NHS National Patient Safety Agency.

Hickman, S. E., Barrick, A. L., Williams, C. S., Zimmerman, S., Connell, B. R., Preisser, J. S., Mitchell, M. \& Sloane, P. D. 2007. The effect of ambient bright light therapy on depressive symptoms in persons with dementia. Journal of the American Geriatrics Society, 55, 1817-1824.

Hospital Episodes Statistics 2005. Hospital Episodes statistics 2004-05. www.hesonline.org.uk: Health and Social Care Information Centre.

Hubbard, R. M., O'Mahony, S. M., Cross, E., Morgan, A., Hortop, H., Morse, R. E. \& Topham, L. 2004. The ageing of the population: implications for multidisciplinary care in hospital. Age and ageing, 33, 479-482.

Kovach, C., Weisman, G., Chaudhury, H. \& Calkins, M. 1997. Impacts of a therapeutic environment for dementia care. American Journal of Alzheimer's Disease and Other Dementias, 12, 99-110.

Lafond, S. 2015. Current NHS spending in England. London, UK: The Health Foundation.

Langa, K. M., Chernew, M. E., Kabeto, M. U., Regula Herzog, A., Beth Ofstedal, M., Willis, R. J., Wallace, R. B., Mucha, L. M., Straus, W. L. \& Fendrick, A. M. 2001. National Estimates of the Quantity and Cost of Informal Caregiving for the Elderly with Dementia*. Journal of General Internal Medicine, 16, 770778.

Lawton, M. P. 1997. Assessing quality of life in Alzheimer disease research. Alz Dis Assoc Disord. , 11, 91-99.

Leon, J. and M.G. Ory, Effectiveness of Special Care Unit (SCU) placements in reducing physically aggressive behaviors in recently admitted dementia nursing home residents. American Journal of Alzheimer's Disease and Other Dementias, 1999. 14(5): p. 270-277.

Lowery, K., Buri, H. \& Ballard, C. 2000. What is the prevalence of environmental hazards in the homes of dementia sufferers and are they associated with falls. International Journal of Geriatric Psychiatry, 15, 883-886.

Luengo-Fernandez, R., Leal, J. \& Gray, A. 2010. Dementia 2010 - The economic burden of dementia and associated research funding in the United Kingdom. In: Oxford, A. S. R. T.-U. O. (ed.). Cambridge.

Marquardt, G. \& Schmieg, P. 2009. Dementia-Friendly Architecture: Environments That Facilitate Wayfinding in Nursing Homes. American Journal of Alzheimer's Disease and Other Dementias, 24, 333-340.

Marshall, M. 2001. Environment: how it helps to see dementia as a disability. Care Homes and Dementia: Journal of Dementia Care, 6.

Marshall, M., Brown M \& Stewart S 1999. Tools for the future. In: Stewart, S., Page, A. \& Laurie, C. (eds.) Making Design Dementia Friendly. Just Anoter Disability. Glasgow, UK: University of Stirling.

Matrix Evidence 2011. Spotlight on dementia care: A Health Foundation improvement report. London, UK: The Health Foundation.

McGilton, K. S., Rivera, T. M. \& P, D. 2003. Can we help persons with dementia find their way in a new environment? Aging \& Mental Health, 7, 363-371.

Melin, L. \& Gotestam, K. G. 1981. The effects of rearranging ward routines on communication and eating behaviours of psychogeriatric patients. . Journal of Applied Behaviour Analysis, 14, 47-51. 
Milligan, G. W. \& Cooper, M. C. 1987. Methodology Review: Clustering Methods. Applied Psychological Measurement, 11, 329-354.

Mills, G. R. W., Deka, L., Price, A. D. F., Rich-Mahadkar, S., Pantzartzis, E. \& Sellars, P. 2015. Critical infrastructure risk in NHS England: predicting the impact of building portfolio age. International Journal of Strategic Property Management, 19, 159-172.

Mitchell, P. \& Bateman, K. 2012. Dementia, falls and fractures. Integrated approaches to improve quality and reduce costs. Synthesis Medical and Novartis.

Monitor 2015. Performance of the foundation trust sector - Year ended 31 March 2015.

Moos, R. \& Lemke, S. 1984. Multiphasic Environmental Assessment Procedure (MEAP): Manual, Palo Alto, US, Social Ecology Laboratory, Veterans Administration, Stanford University Medical Center.

Morgan-Brown, M., Newton, R. \& Ormerod, M. 2012. Engaging life in two Irish nursing home units for people with dementia: Quantitative comparisons before and after implementing household environments. Aging \& Mental Health, 17, 57-65.

Myers, H. 2003. Hospital fall risk assessment tools: A critique of the literature. International Journal of Nursing Practice, 9, 223-235.

National Institute for Health and Clinical Excellence 2004. Falls. The assessment and prevention of falls in older people. . NICE.

NHS Estates 2004. A risk-based methodology for establishing and managing backlog London: The Stationery Office.

Noblit, G. W. \& Hare, R. D. 1988. Meta-ethnography:synthesising qualitative studies., London, Sage.

Oliver, D., Daly, F., Martin, F. C. \& McMurdo, M. E. T. 2004. Risk factors and risk assessment tools for falls in hospital in-patients: a systematic review. Age and ageing, 33, 122-130.

Phillips, C. D., Sloane, P. D., Hawes, C. \& et al. 1997. Effects of residence in alzheimer disease special care units on functional outcomes. JAMA, 278, 1340-1344.

Price, A. D. F., Pantzartzis, E. \& Pascale, F. 2015. Improving the environment of care for people with dementia. Final Recommendations Report. Executive Summary.: Department of Health.

Ray, S. \& Davidson, S. 2014. Dementia, cognitive decline and services: A review of the evidence.: Age UK Research.

Reimer, M. A., Slaughter, S., Donaldson, C., Currie, G. \& Eliasziw, M. 2004. Special care facility compared with traditional environments for dementia care: A longitudinal study of quality of life. Journal of the American Geriatrics Society, 52, 1085-1092.

Robustillo, S. A., Corsini, V., Marcu, V., Vasileva, K., ESTAT, D., Marchetti, E. \& EMPL, D. 2013. EU Employment and Social Situation. In: Commission, E. (ed.). Luxembourg: European Commission.

Satlin, A., Volicer, L., Ross, V., Herz, L. \& Campbell, S. 1992. Bright light treatment of behavioral and sleep disturbances in patients with Alzheimer's disease. American Journal of Psychiatry, 149, 1028-1032.

Schaller, S., Mauskopf, J., Kriza, C., Wahlster, P. \& Kolominsky-Rabas, P. L. 2015. The main cost drivers in dementia: a systematic review. International Journal of Geriatric Psychiatry, 30, 111-129. 
Skelton, D. A. \& Todd, C. J. 2005. Thoughts on effective falls prevention intervention on a population basis. Journal of Public Health, 13, 196-202.

Sloane, P. D., Mitchell, C. M., Preisser, J. S., Phillips, C., Commander, C. \& Burker, E. 1998. Environmental correlates of resident agitation in Alzheimer's disease Special Care Units. Journal of the American Geriatrics Society, 46, 862-869.

Sloane, P. D., Mitchell, C. M., Weisman, G., Zimmerman, S., Foley, K. M. L., Lynn, M., Calkins, M., Lawton, M. P., Teresi, J., Grant, L., Lindeman, D. \& Montgomery, R. 2002. The Therapeutic Environment Screening Survey for Nursing Homes (TESS-NH): An Observational Instrument for Assessing the Physical Environment of Institutional Settings for Persons With Dementia. The Journals of Gerontology Series B: Psychological Sciences and Social Sciences, 57, S69-S78.

Sloane, P. D., Williams, C. S., Mitchell, C. M., Preisser, J. S., Wood, W., Barrick, A. L., Hickman, S. E., Gill, K. S., Connell, B. R., Edinger, J. \& Zimmerman, S. 2007. High-Intensity Environmental Light in Dementia: Effect on Sleep and Activity. Journal of the American Geriatrics Society, 55, 1524-1533.

The National Patient Safety Agency, Slips, trips and falls in hospital. 2007, London, UK: NPSA.

Thorpe, L., Middleton, J., Russell, G. \& Stewart, N. 2000. Bright light therapy for demented nursing home patients with behavioral disturbance. American Journal of Alzheimer's Disease and Other Dementias, 15, 18-26.

Van Doorn, C., Gruber-Baldini, A. L., Zimmerman, S., Richard Hebel, J., Port, C. L., Baumgarten, M., Quinn, C. C., Taler, G., May, C., Magaziner, J. \& for the Epidemiology of Dementia in Nursing Homes Research, G. 2003. Dementia as a Risk Factor for Falls and Fall Injuries Among Nursing Home Residents. Journal of the American Geriatrics Society, 51, 1213-1218.

van Hoof, J., Aarts, M. P. J., Rense, C. G. \& Schoutens, A. M. C. 2009. Ambient bright light in dementia: Effects on behaviour and circadian rhythmicity. Building and Environment, 44, 146-155.

Walsh, D. \& Downe, S. 2005. Meta-synthesis method for qualitative research: a literature review. Journal of Advanced Nursing, 50, 204-211.

Wanless, D. 2006. Securing Good Care for Older People.Taking a long-term view. In: Fund, T. K. S. (ed.). The King's Fund.

Weed, M. 2005. "Meta Interpretation": A Method for the Interpretive Synthesis of Qualitative Research. 2005, 6.

Wells, Y. \& Jorm, A. F. 1987. Evaluation of a special nursing home unit for dementia sufferers: a randomised controlled comparison with community care. The Australian and New Zealand journal of psychiatry, 21, 524-531.

WHO - National Institute on Aging - National Institutes of Health 2011. Global health and ageing. WHO.

WHO 2004. ICD-10 2nd edition. Geneva: World Health Organisation.

WHO 2012. Dementia: a public health priority. Geneva: Alzheimer's Disease International - WHO.

Wimo, A., Jönsson, L., Gustavsson, A., McDaid, D., Ersek, K., Georges, J., Gulácsi, L., Karpati, K., Kenigsberg, P. \& Valtonen, H. 2011. The economic impact of dementia in Europe in 2008 — cost estimates from the Eurocode project. International Journal of Geriatric Psychiatry, 26, 825-832.

Wimo, A., Winblad, B. \& Jönsson, L. 2007. An estimate of the total worldwide societal costs of dementia in 2005. Alzheimer's \& Dementia, 3, 81-91. 
Wood, W., Harris, S., Snider, M. \& Patchel, s. A. 2005. Activity situations on an Alzheimer's disease special care unit and resident environmental interaction, time. American Journal of Alzheimer's Disease and Other Dementias, 20, 105116.

Zeisel, J., Silverstein, N. M., Hyde, J., Levkoff, S., Lawton, M. P. \& Holmes, W. 2003. Environmental correlates to behavioral health outcomes in Alzheimer's special care units. Gerontologist, 43, 697-711. 